\title{
MicroRNA-182 suppresses clear cell renal cell carcinoma migration and invasion by targeting IGF1R
}

\author{
X. WANG ${ }^{1,2, \neq}$, H. LI $I^{2, *}$ L. CUI ${ }^{2}$, J. FENG ${ }^{3}$, Q. FAN ${ }^{1, *}$
}

${ }^{1}$ Department of Oncology, The First Affiliated Hospital of Zhengzhou University, Zhengzhou 450052, Henan, P.R. China; ${ }^{2}$ Department of Pathology, The First Affiliated Hospital of Zhengzhou University, Zhengzhou 450052, Henan, P.R. China; ${ }^{3}$ Department of Respiratory Medicine, Zhengzhou YIHE Hospital, Zhengzhou 450047, Henan, P.R. China

*Correspondence: qingxiafan398@126.com

${ }^{*}$ Contributed equally to this work.

Received January 25, 2016 / Accepted May 16, 2016

\begin{abstract}
The purpose of our study was aimed to determine the functional role of microRNA (miR)-182 in clear cell renal cell carcinoma (ccRCC) and try to clarify its underlying molecular mechanism. Expression of miR-182 in both cancer and peripheral blood samples was analyzed by quantitative real-time PCR (qRT-PCR). Human RCC line Caki-1 cells were transfected with miR-182 mimic, miR-182 inhibitor, or negative controls, and then the cell viability, colony-formation ability, migration, and invasion assay were determined. Luciferase reporter assay, qRT-PCR and Western blotting were used to determine whether insulin-like growth factor 1 receptor (IGF1R) was a target of miR-182. Further, small interfering RNA (siRNA) against IGF1R was co-transfected with miR-182 inhibitor into cells, and then the effects on migration and invasion were assessed. MiR-182 was down-regulated in both cancer and blood samples compared to the matched non-tumor adjacent tissues and healthy volunteers, respectively (both $\mathrm{P}<0.05$ ). Compared to the control group, cell viability, colony-forming ability, and numbers of migrated and invaded cells were significantly decreased by transfection with miR-182 mimic but were markedly increased by miR-182 inhibitor (all P < 0.05). Luciferase reporter assay confirmed that IGF1R was a target gene of miR-182, and IGF1R was negatively regulated by miR-182. Co-transfection of miR-182 inhibitor with si-IGF1R reversed the effect of miR-182 inhibitor on the migration and invasion of the cells. MiR-182 functions as an anti-oncogene in ccRCC, and miR-182-mediated inhibition of cell migration and invasion might be through directly targeting IGF1R.
\end{abstract}

Key words: MicroRNA-182, clear cell renal cell carcinoma, migration and invasion, insulin-like growth factor 1 receptor

Renal cell carcinoma (RCC) is the most common malignant tumor of adult kidney and accounts for approximately $3 \%$ of adult cancers with a high mortality at over $40 \%[1,2]$. Clear cell renal cell carcinoma (ccRCC) is the most frequent subtype of RCC accounting for about $75-80 \%$ of the tumor [3]. Despite a tremendous advance has been made in available treatments, the prognosis still remains dismal for locally advanced and metastatic RCC [4]. It has been reported that up to $30-40 \%$ of patients with RCC present with metastatic disease even after radical resections [5]. Therefore, it is necessary to provide knowledge of molecule mechanisms controlling the metastatic and invasive potential of RCC.

MicroRNAs (miRNAs) are a class of small and non-coding RNA molecules that regulate mRNA transcription and translation by base pairing with the $3^{\prime}$ untranslated region (UTR) [6]. It has been well demonstrated that miRNAs are involved in the development and progression of various cancers by regulating cell proliferation, invasion, and migration $[7,8]$. Recently, emerging evidence has suggested the significant roles of miRNAs in RCC [9-11]. Among miRNAs, miR-182 was recently found to be associated with the invasive and/or metastatic potential of prostate cancer [12], melanoma [13], and ovarian carcinomas [14]. However, little information is available regarding the relationship between miR-182 and RCC migration and invasion.

In the present study, we explored the functional role of miR-182 in RCC migration and invasion. The expression pattern of miR-182 in both ccRCC tumor tissues and peripheral blood samples were first investigated. The effects of miR-182 on ccRCC cell viability, migration, and invasion were then determined by altering the endogenous levels of miR-182 in renal carcinoma cell line cell line Caki-1 cells. We further 
predicted the direct targets of miR-182 to clarify the underlying mechanism of migration and invasion in ccRCC. Our study may provide new targets for intervention of ccRCC by decreasing the migrated and invaded cells.

\section{Patients and methods}

Patients and specimens. Human kidney specimens, including ccRCC and their matched non-tumor adjacent tissue samples $(>5 \mathrm{~cm}$ ), were obtained from 57 patients ( 38 males and 19 females, aged 50-79 years old) who underwent radical nephrectomy at the First Affiliated Hospital of Zhengzhou University between April 2010 and August 2015. The specimens were immediately snap-frozen and stored at $-80^{\circ} \mathrm{C}$. The pathologic diagnosis of ccRCC was confirmed according to the 2004 World Health Organization classification [15]. No previous local or systemic treatment was performed to the patients. Additionally, two-milliliter peripheral blood samples were collected from both the patients and 10 healthy volunteers. The collection and use of the samples were approved by the Institutional Ethics Committee of First Affiliated Hospital of Zhengzhou University, and written consents were obtained from all the enrolled participants.

Cell culture. The human RCC line cell line Caki-1 cells were obtained from the Shanghai Institute of Cell Biology at the Chinese Academy of Sciences (Shanghai, PR China). The cells were grown in McCoy's 5A medium (Invitrogen) supplemented with $10 \%$ fetal bovine serum (FBS) (GIBCO, Grand Island, NY, USA), $100 \mathrm{U} / \mathrm{ml}$ penicillin and $100 \mu \mathrm{g} /$ $\mathrm{ml}$ streptomycin (Life Technologies) at $37^{\circ} \mathrm{C}$ in a humidified atmosphere of $5 \% \mathrm{CO}_{2}$.

Transfection. Caki-1 cells were transiently transfected with miR-182 mimic, miR-182 inhibitor, miR-control RNA, small interfering RNA (siRNA) against IGF1R, or siRNA-control using Lipofectamine 2000 (Invitrogen) according to the manufacturer's instructions. The miR-182 mimic and inhibitor, si-IGF1R, and their corresponding negative controls were designed and produced by GenePharma (Shanghai, China). In brief, the cells were seeded in a 24-well and incubated for $24 \mathrm{~h}$, the cells were then transiently transfected with miR-182 mimic $(50 \mathrm{nM})$, miR-182 (50 nM), or si-IGF1R (100 nM). After 48 $h$, the cells were harvested for further analyses.

RNA preparation and quantitative real time-PCR (qRTPCR). Total RNA including miRNAs was extracted from tissue samples, peripheral blood samples, or Caki-1 cells using TRIzol reagent (Invitrogen) following the manufacturer's protocol. For analysis of miR-182 expression, reverse transcription and stem-loop RT-PCR were performed using the TaqMan MicroRNA assays (Applied Biosystems, Foster City, CA, USA) and amplified by TaqMan Universal PCR Master Mix (Applied Biosystems). U6 snRNA was probed as a loading control. For analysis of IGF1R expression, qRT-PCR was carried out using SYBR green PCR master mix (Applied Biosystems). Total RNA was reverse-transcribed, amplified and detected according to the manufacturer's instructions.
GAPDH was used as a loading control. Both reverse transcription and primers were obtained from Genepharma (Shanghai, China). All samples were run in triplicate and the data were analyzed by using the comparative $2^{-\Delta \Delta C T}$ methods.

Cell viability. The cell viability was determined by $3-(4$, 5-dimethyl-2-thiazolyl)-2, 5-diphenyl-2-H-tetrazolium bromide (MTT) assay. Briefly, Caki-1 cells were seeded in a 96-well plate for $24 \mathrm{~h}$ before transfection. The cells were then incubated with MTT $(5 \mathrm{mg} / \mathrm{mL}, 20 \mu \mathrm{L})$ at $37^{\circ} \mathrm{C}$ for 5 $\mathrm{h}$ and lysed in dimethyl sulfoxide (DMSO) $(150 \mu \mathrm{L})$ at room temperature for $10 \mathrm{~min}$ at $24,48,72$ and $96 \mathrm{~h}$ after transfection. The optical density (OD) was measured at $450 \mathrm{~nm}$ with $650 \mathrm{~nm}$ as a reference using a Synergy plate reader (BioTek, Winooski, VT, USA). Assays were run in triplicate.

Cell colony formation. The cells were seeded in 6-well plates at a density of 1000 cells per well. After 24 of incubation, the cells were transfected with miR-182 mimic, inhibitor, or negative controls and allowed to grow for 14 days until visible clones appeared. Subsequently, the cells were collected, washed with phosphate buffer saline (PBS), fixed with $4 \%$ paraformaldehyde, and stained with $0.1 \%$ crystal violet solution. The number of colonies was scored visually under a fluorescence microscope (IX71, Olympus, Tokyo, Japan).

Cell migration and invasion assay. Cell migration and invasion were measured using Transwell migration chambers (8 $\mu \mathrm{m}$ pore size; Corning, NY, USA). The upper-chamber membranes were coated with a diluted Matrigel (BD Biosciences) for the invasion assay, and while the upper-chamber membranes were without Matrigel for the migration assay. For both the assays, the cells $\left(5 \times 10^{4}\right.$ cells/well $)$ were transfected, starved overnight, trypsinized, and seeded in the upper chambers with serum-free medium. The bottom chamber was filled with 10 $\%$ FBS which acted as a chemoattractant. After incubation for $24 \mathrm{~h}$ at $37^{\circ} \mathrm{C}$, the migrated or invaded cells were fixed with $4 \%$ paraformaldehyde, stained with $0.5 \%$ crystal violet solution, and counted with a light microscopy.

Target prediction. TargetScan 6.2 (http://www.targetscan. org) and/or microRNA.org (http: //www. microrna.org) were used to predict target genes of miR-182.

Luciferase reporter assay. Caki-1 cells were seeded in 48well plates 24 prior to the transfection. The 3'-UTR sequence of wild-type (WT) or mutated (Mut) human IGF1R was PCRamplified and linked into the psiCHECK vector (GenePharma) at $70 \%-80 \%$ cell confluence. Forty-eight hours later, firefly and renilla luciferase activities were measured consecutively by using Dual Luciferase Assay (Promega, USA) according to the manufacturer's instructions. Tests were performed in duplicate in three independent samples.

Western blot analysis. The expression levels of IGF1R were measured by Western blotting using standard protocols. Briefly, protein was extracted from Caki- 1 cells after transfection with miR-182 mimic or inhibitor, or si-IGF1R. The concentration of protein was determined by using Bio-Rad protein assay reagent (Bio-Rad Laboratories, CA, USA). The protein samples were separated by $10-12 \%$ sodium dodecyl 
sulfate (SDS) - polyacrylamide gel electrophoresis and blotted onto polyvinylidene fluoride (PVDF) membranes (GE Healthcare, Little Chalfont, England). Membranes were then probed with IGF1R antibody (Cell Signaling Technology, Inc. Danvers, $\mathrm{MA}$ ) at $4^{\circ} \mathrm{C}$ overnight. After incubation with horseradish peroxidase (HRP) secondary antibody (Cell Signaling Technology), the blotted proteins were visualized using enhanced chemiluminescence (Amersham Pharmacia Biotech Inc, Piscataway, NJ). GAPDH was used as a loading control.

Statistical analysis. All data were shown as mean \pm standard deviation (SD). Statistical analyses were conducted using SAS software (SAS Institute, version 9.2). A P-value of $<0.05$ was considered to be statistically significant.

\section{Results}

MiR-182 was decreased in both ccRCC and blood samples. To evaluate the functional role of miR-182 in ccRCC, we first determined the expression levels of miR182 in both ccRCC and blood samples by using qRT-PCR analysis. Tissue samples, including ccRCC and their matched non-tumor adjacent tissue samples, were obtained from 57 patients with ccRCC. Circulating miRNAs in the serum have been regarded as noninvasive biomarkers in many cancers, thus, we explored whether serum miR-182 expression was a biomarker of ccRCC. Peripheral blood samples were collected from all the patients and 10 healthy volunteers. The results revealed that the relative expression levels of miR182 were significantly decreased in cancer tissues compared to the matched non-tumor tissues $(P<0.05)$ (Figure $1 \mathrm{~A}$ ). Similarly, the expression of miR-182 in the peripheral blood was also significantly lower in the patients with ccRCC than that in the healthy volunteers $(P<0.05)$, implying that serum miR-182 expression might be a novel biomarker of ccRCC (Figure $1 \mathrm{~B}$ ). These data suggested miR-182 might play a key role in ccRCC.

MiR-182 decreased cell viability, migration, and invasion. We then assessed the functional role of miR-182 in ccRCC. The expression of miR-182 was altered by transfection with miR-182 mimic or inhibitor. The transfection efficiency was evaluated by qRT-PCR. As shown in Figure 2 A, the relative expression levels of miR-182 was significantly up-regulated by transfection with miR-182 mimic but was statistically downregulated by transfection with miR-182 inhibitor compared with the control group (both $P<0.05$ ). After transfection, the cell viability and cell colony formation was determined. As indicated in Figure 2 B-D, compared to the control group, both the cell viability and colony-formation ability were significantly decreased by transfection with miR-182 mimic, but markedly increased by transfection with miR-182 inhibitor (both $P<0.05$ ). The effects of miR-182 on migration and invasion in Caki-1 cells were further investigated. We found that the numbers of migrated and invaded cells were both significantly decreased by miR-182 mimic but were obviously
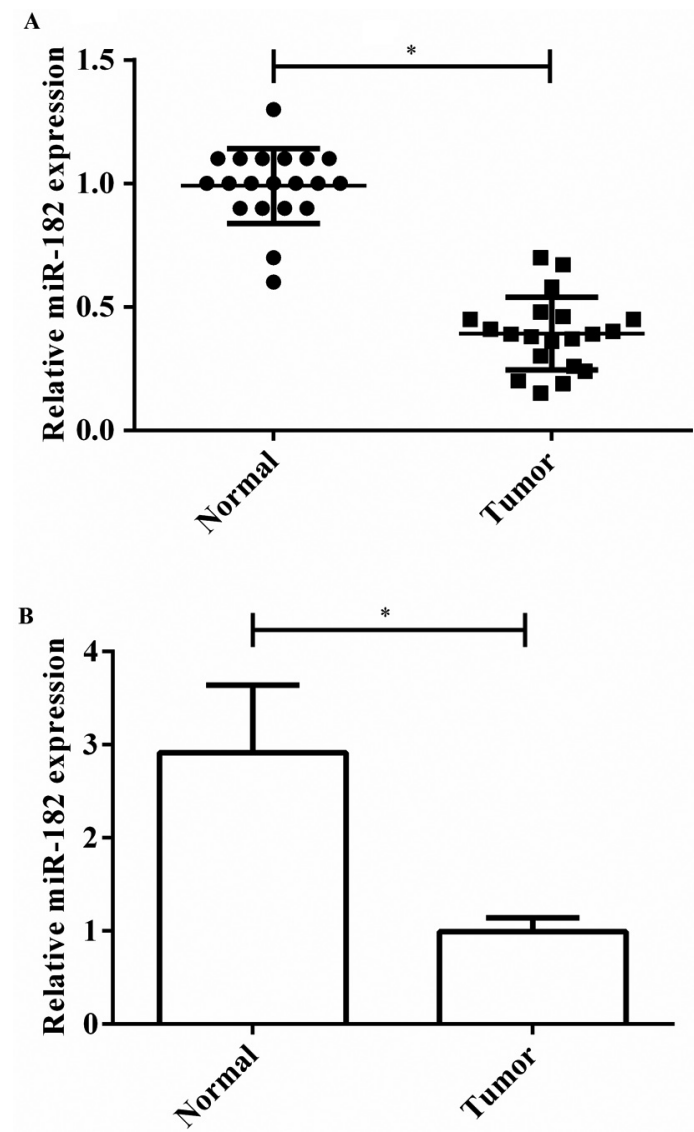

Figure 1. The relative expression levels of miR-182 in both tumor and blood samples. A, compared to the matched non-tumor adjacent tissue samples, the relative expression levels of miR-182 is significantly decreased in tumor samples; B, compared to healthy volunteers, the relative expression levels of miR-182 is markedly decreased in blood samples. ${ }^{*} P<0.05$ compared to normal group

elevated by miR-182 inhibitor (both $P<0.05$ ) (Figure $3 \mathrm{~A}-\mathrm{D}$ ). These data indicated that miR-182 might function as an antioncogene in ccRCC by inhibition of cell viability, migration, and invasion.

IGF1R was a direct target of miR-182. To determine how miR-182 exerts its cell migration and invasion inhibitory functions, two algorithm programs (TargetScan 6.2 and microRNA.org) were used to predict potential target genes. IGF1R was chosen as one of the candidate genes because its 3'UTR contained several potential binding sites of miR-182 and it was responsible for cell migration and invasion. As shown in Figure 4 A, IGF1R was predicted to be a target of miR-182. To confirm the results, we determined the expression levels of IGF1R after changing the expression of miR-182. Overexpression of miR-182 led to a decrease of IGF1R mRNA and protein levels in Caki-1 cells. Conversely, inhibiting the expression of miR-182 resulted in an increase of IGF1R mRNA and protein levels in Caki-1 cells (Figure 4 B and C). 

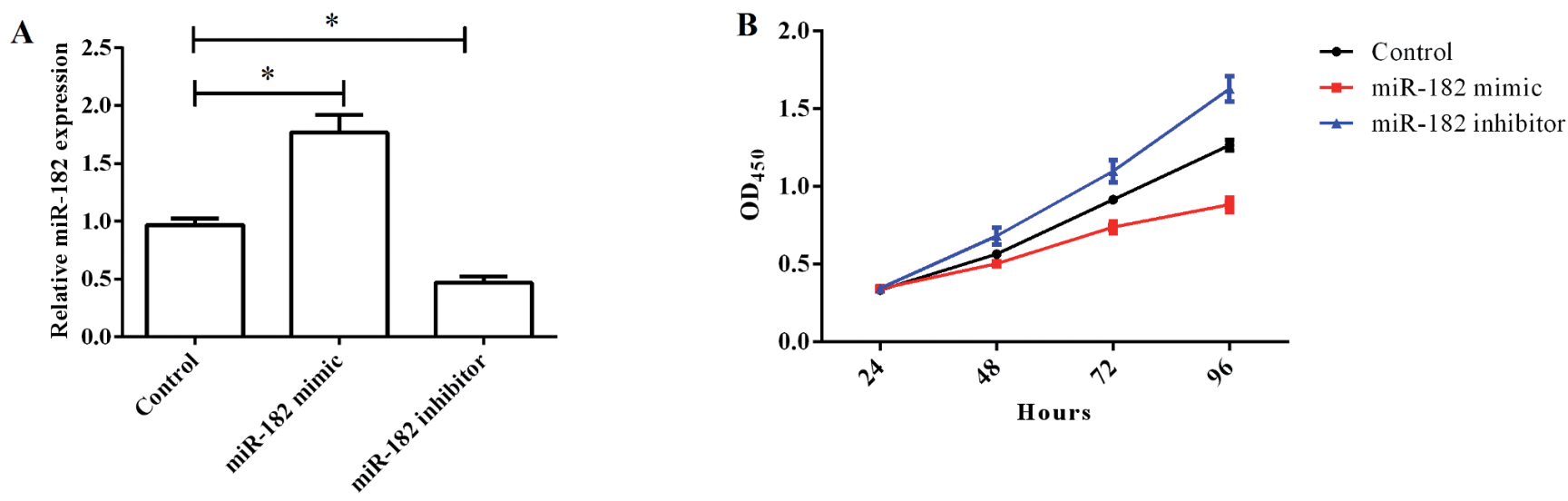

C
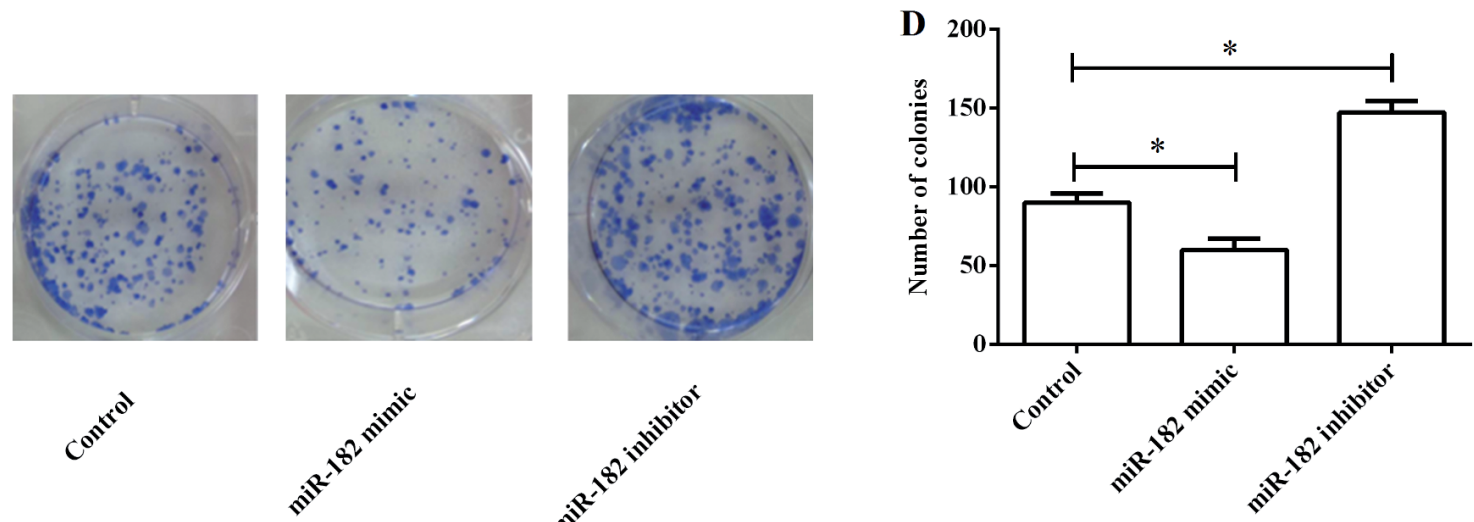

Figure 2. The effect of miR-182 on cell viability in Caki-1 cells. A, the relative levels of miR-182 is significantly up-regulated by transfection with miR182 mimic but is statistically down-regulated by transfection with miR-182 inhibitor compared with the control group; B, cell viability is significantly decreased by transfection with miR-182 mimic, but markedly increased by transfection with miR-182 inhibitor; C-D, colony-formation ability is significantly decreased by transfection with miR-182 mimic, but markedly increased by transfection with miR-182 inhibitor. OD, optical density, ${ }^{*}<$ 0.05 compared to control group

To further validate whether IGF1R was indeed directly regulated by miR-182 in Caki- 1 cells, the target sequence of IGF1R 3'UTR (WT- IGF1R 3'UTR) or the mutant sequence (Mut-IGF1R 3'UTR) was cloned into a luciferase reporter vector. The results of luciferase assay showed that the luciferase activity was significantly decreased by co-transfection of miR182 with IGF1R 3'UTR WT in Caki-1 cells, but no significant differences could be found by co-transfection of miR-182 mimic with IGF1R 3'UTR Mut (Figure 4 D). The detailed sequence of IGF1R 3'UTR WT or Mut were shown in Figure 4 E. Taken together, these results strongly suggested that IGF1R was a direct target of miR-182 in the ccRCC cells.

MiR-182-mediated inhibition of cell migration and invasion was through directly targeting IGF1R. In spite of the above results suggested that miR-182 can directly inhibit the expression of IGF1R, it has not been confirmed that whether miR-182-mediated inhibition of cell migration and invasion is through targeting IGF1R. Therefore we examined whether inhibition of IGF1R activity could reverse the role of cell migration and invasion inhibition by miR-182 in Caki-1 cells. The expression of IGF1R was silenced by transfection with
siRNA targeting IGF1R. As shown in Figure $5 \mathrm{~A}$ and B, both the mRNA and protein expression levels of IGF1R were significantly decreased by transfection with si-IGF1R $(P<0.05)$. After co-transfection of miR-182 inhibitor with si-IGF1R, the numbers of migrated and invaded cells were statistically downregulated compared to the cells only transfected by miR-182 inhibitor $(P<0.05)$ (Figure $5 \mathrm{C}-\mathrm{F})$. The results indicated that miR-182-mediated inhibition of cell migration and invasion was through directly targeting IGF1R inhibition.

\section{Discussion}

In the present study, we focused on the functional role of miR-182 in ccRCC, as well as possible regulatory mechanism. Our data demonstrated that the expression of miR-182 was significantly decreased in ccRCC tumor tissues and peripheral blood samples. Overexpression of miR-182 statistically decreased the cell viability, colony-formation ability, migration, and invasion of RCC line Caki- 1 cells. Additionally, we found that IGF1R was a direct target gene of miR-182 and was negatively regulated by $\mathrm{miR}-182$. The results suggest that miR- 
A
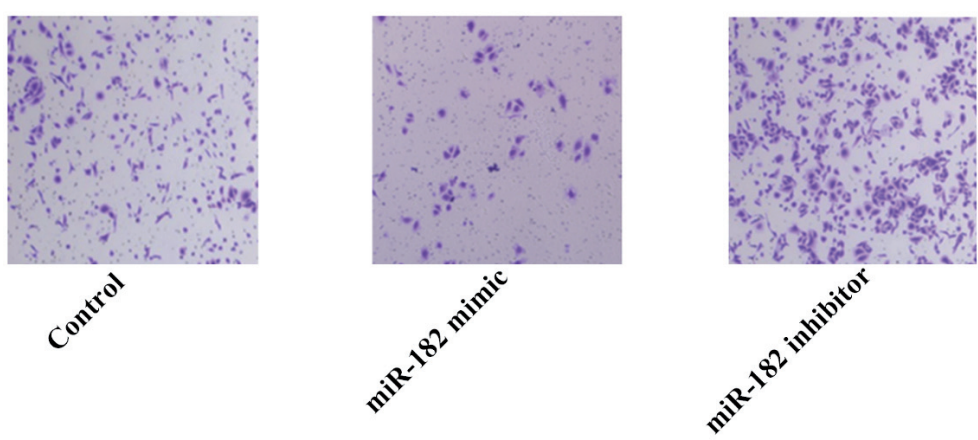

C
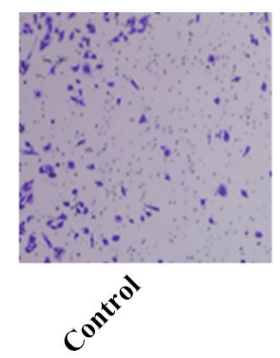
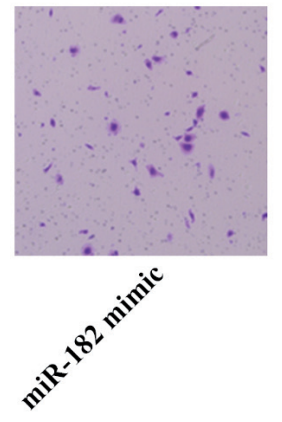

B

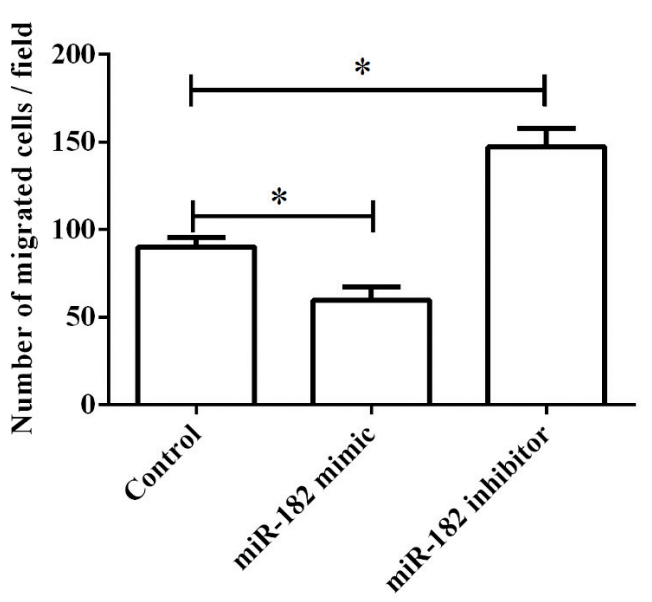

D

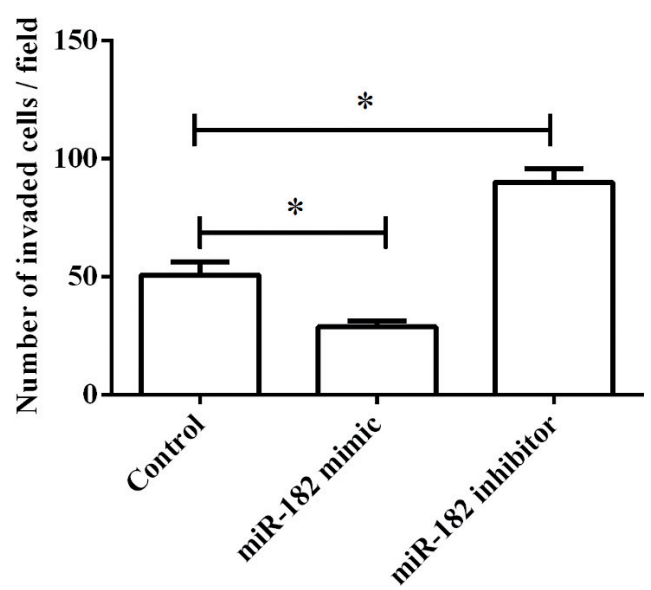

Figure 3. The effect of miR-182 on migration and invasion in Caki-1 cells. A-B, the numbers of migrated cells are significantly decreased by miR-182 mimic but obviously elevated by miR-182 inhibitor; C-D, the numbers of invaded cells are significantly decreased by miR-182 mimic but obviously elevated by miR-182 inhibitor. ${ }^{\star} P<0.05$ compared to control group

182 might function as an important tumor suppressor gene in ccRCC, and miR-182-mediated inhibition of cell migration and invasion is through directly targeting IGF1R.

Accumulating evidence suggests that miRNAs play significant roles in regulation multiple biological processes, including the migration and invasion [16-18]. Among mRNAs, the function of miR-182 is complicated because miR-182 has been identified as an oncogene or an anti-oncogene in the context of different cancers. For example, Sun et al. has suggested that miR-182 serves as an anti-oncogene by suppressing lung cancer cell proliferation and anchorage-independent cell growth through down regulation of regulator of G-protein signaling 17 (RGS17) expressions in vitro [19]. Tang et al. found that miR-182 was significantly downregulated in human gastric tissue samples, and inhibits proliferation and colony formation of gastric cancer cells through targeting oncogenic ANUBL1 (also known as zinc finger, AN1-type domain 4 (ZFAND4)) [20]. However, Wang et al. found that miR-182 was significantly up-regulated in hepatocellular carcinoma (HCC) and promoted metastasis of HCC by inhibition of metastasis suppressor 1 (MTSS1) expression [21]. The functional role of miR-182 in RCC has been recently investigated. $\mathrm{Xu}$ and co-workers found that miR-182-5p was frequently down-regulated in human RCC tissues and enforced expression of miR-182-5p significantly inhibited the proliferation and tumorigenicity in vitro and in vivo [22]. However, little research has been performed regarding migration and invasion of miR-182 in ccRCC. Therefore, our study aimed to elucidate the effect of miR-182 on ccRCC migration and invasion, as well as the underlying mechanisms. In the present study, we first determined the expression levels of miR-182 in both the tumor and peripheral blood samples. Our results indicated that compared to the matched non-tumor adjacent tissues and normal blood samples, the expression levels of miR182 were significantly decreased in both cancer and blood samples. The results highlighted a critical role for miR-182 
in the pathogenesis of ccRCC, and serum miR-182 might be a biomarker of ccRCC, which were in line with Xu et al. [22]. Next, we assessed the effect of miR-182 on ccRCC cells. The endogenous expression of miR-182 was changed, and then the cell viability, colony-formation ability, migration, and invasion ability were determined. Our findings demonstrated that miR182 functioned as a tumor suppressor in ccRCC by decreasing cell viability, migration, and invasion ability.
The possible mechanism regarding migration and invasion of miR-182 was further investigated. Migration and invasion have been considered to be one of the most important determinants in the development and progression of tumor metastasis, which contribute to the leading causes of morbidity and mortality. The development of metastasis is a multistage process that is involved in many factors such as lymphangiogenesis, angiogenesis, and invasiveness of cancer cells [23, 24]. It has

A

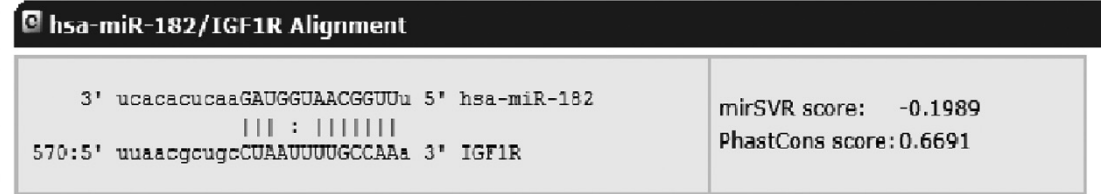

Mouseover a miRNA mature name to see the miRNA/IGF1R alignment.

B

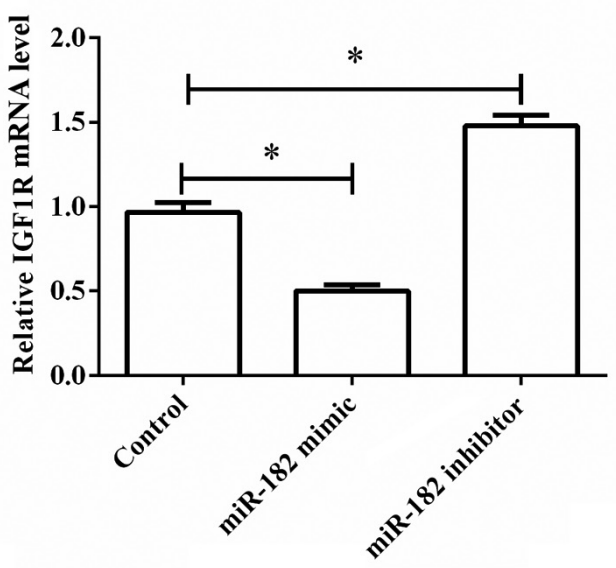

D

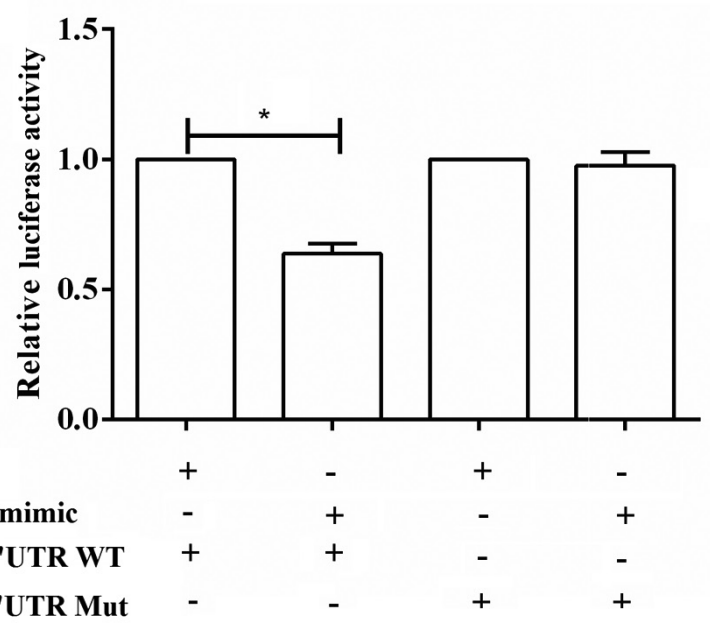

miR-Ctr

miR-182 mimic

IGF1R 3'UTR W'

IGF1R 3'UTR Mut
C

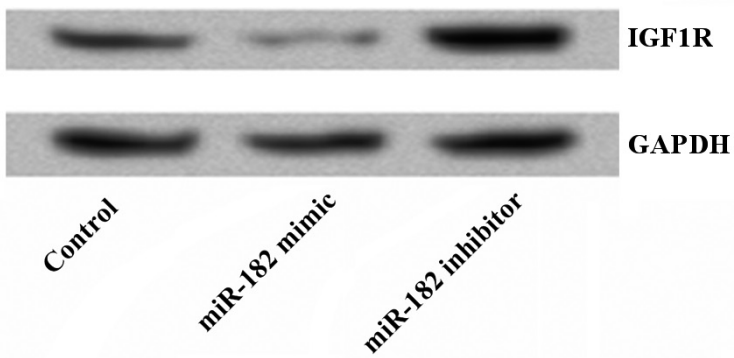

E

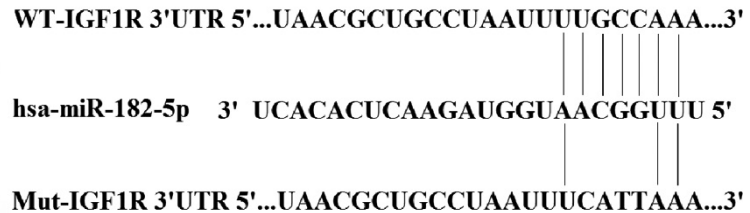

Figure 4. The relationship between IGF1R and miR-182. A, IGF1R is predicted to be a target gene of miR-182; B, IGF1R mRNA levels are significantly decreased by miR-182 mimic but increased by miR-182 inhibitor; C, IGF1R protein levels are significantly decreased by miR-182 mimic but increased by miR-182 inhibitor; D, luciferase reporter assay confirms that IGF1R is directly regulated by miR-182; E, the detailed sequence of IGF1R 3'UTR WT or Mut. ${ }^{*} P<0.05$ compared to control group 
A

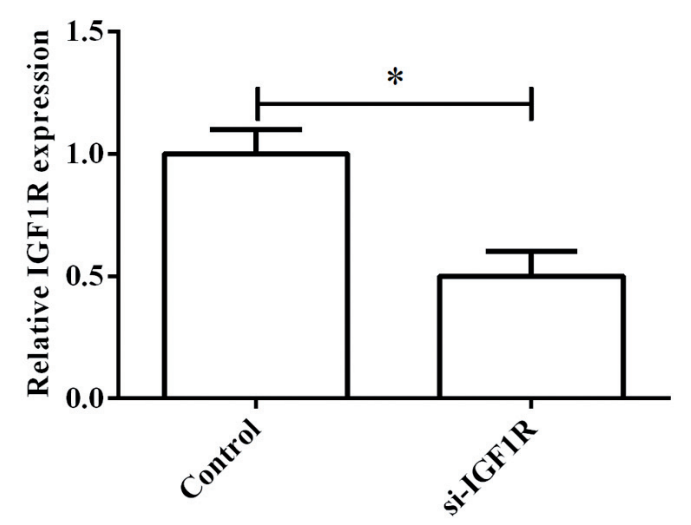

C

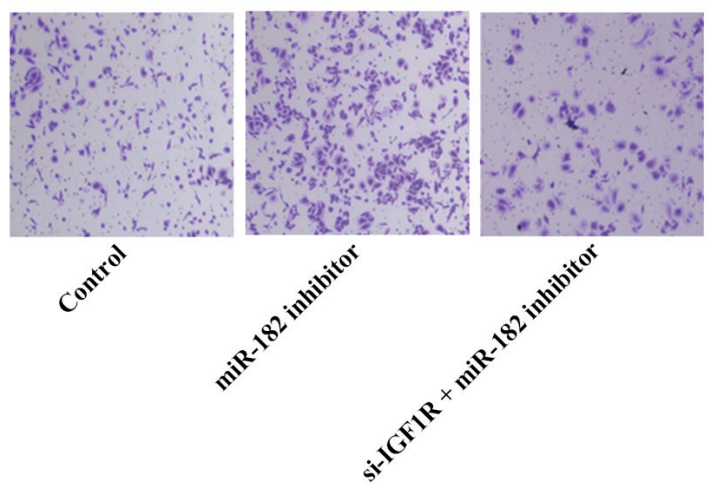

E
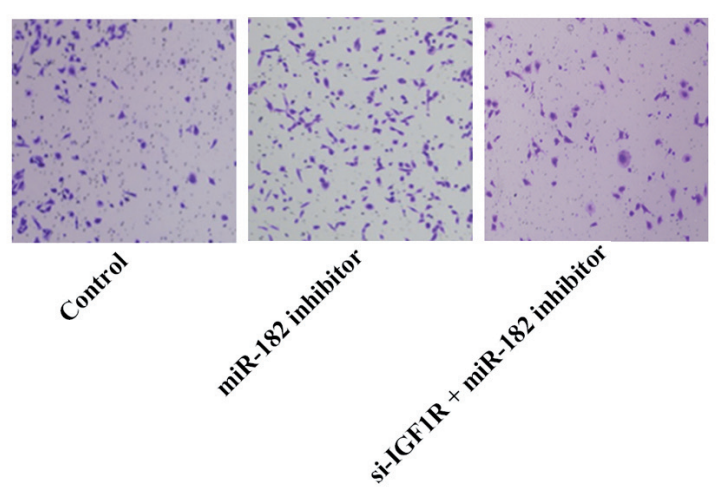

B

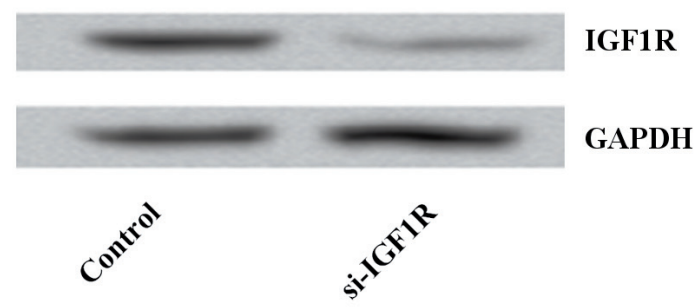

D

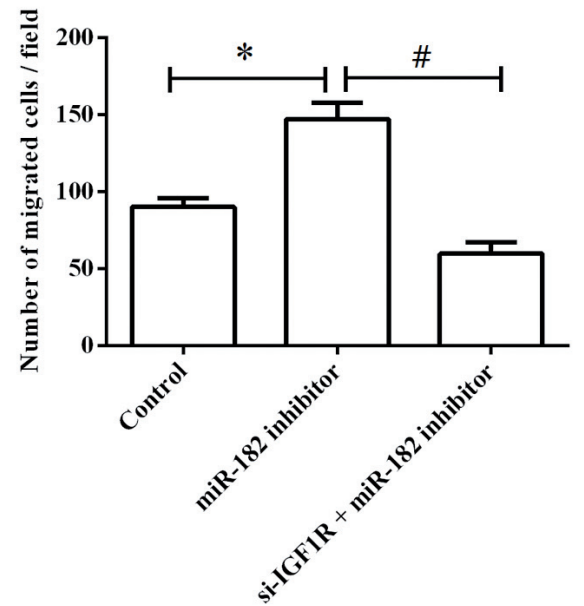

F

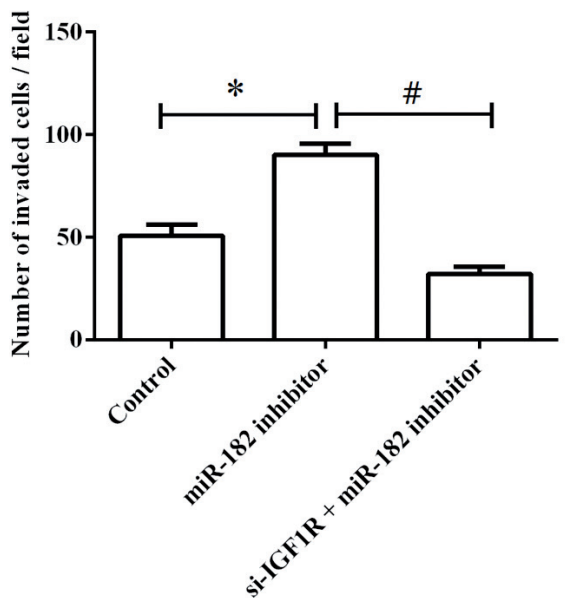

Figure 5 MiR-182-mediated inhibition of cell migration and invasion is through directly targeting IGF1R. A-B, the mRNA and protein levels of IGF1R are significantly decreased by transfection with si-IGF1R; C-D, the numbers of migrated cells are statistically down-regulated by co-transfection of miR182 inhibitor with si-IGF1R; E-F, the numbers of invaded cells are statistically down-regulated by co-transfection of miR-182 inhibitor with si-IGF1R. ${ }^{*} P<0.05$ compared to control group, ${ }^{*} P<0.05$ compared to miR-182 inhibitor group 
been reported that metastases were present in up to $60-70 \%$ of patients by the time of diagnosis [24]. In addition, metastasis can be an early event feature and stay unnoticed until the diagnosis because of the asymptomatic status in the early stage $[25,26]$. Therefore, better understanding of the regulatory mechanisms of migration and invasion of malignancy may provide new target therapeutic interventions against cancers. In the present study, we tried to clarify the underlying regulatory mechanism of miR-182 in ccRCC migration and invasion. Our results showed that IGF1R was a direct target gene of miR182 , and was negatively regulated by miR-182. IGF1R is an important oncogene, which is often mutated or overexpressed in many human tumors including RCC [27]. It has been well demonstrated that IGF1R mediates tumor cell proliferation, differentiation, survival, migration, and apoptosis [28-30]. Furthermore, a growing body of evidence points out that IGF1R is essential for oncogenic transformation and is responsible for critical process of the metastatic cascade such as angiogenesis, cell adhesion, migration, and invasion [30, 31]. Additionally, IGF1R has been regarded as a valuable therapeutic target, and IGF1R-antagonistic monoclonal antibodies have been raised against the activity of IGF1R [32]. Several miRNAs, such as miR-133, miR-143, miR-145, and miR-503 [33-35], have been shown the ability to target IGF1R gene expression in different tumors. Our results also found that IGF1R was a direct target of miR-182 by luciferase reporter assay, and IGF1R could be negatively regulated by miR-182. To confirm whether miR182 regulates the migration and invasion in ccRCC cells by regulating the expression of IGF1R, we determined the effect of silencing of IGF1R on the migration and invasion in ccRCC cells. The results showed that silencing the expression of IGF1R reversed the effect of miR-182 inhibitor on the migration and invasion of the cells.

In conclusion, our results suggest that miR-182 may function as a new metastasis-related gene in ccRCC. MiR-182 suppresses the migration and invasion of ccRCC cells by negatively regulating the expression of IGF1R.

Acknowledgements: This study was supported by Young Foundation of the First Affiliated Hospital of Zhengzhou University.

\section{References}

[1] YI Z, FU Y, ZHAO S, ZHANG X, MA C. Differential expression of miRNA patterns in renal cell carcinoma and nontumorous tissues. J Cancer Res Clin Oncol 2010; 136: 855-862. http://dx.doi.org/10.1007/s00432-009-0726-x

[2] CHOW TF, YOUSSEF YM, LIANIDOU E, ROMASCHIN $\mathrm{AD}, \mathrm{HONEY}$ RJ et al. Differential expression profiling of microRNAs and their potential involvement in renal cell carcinoma pathogenesis. Clin Biochem 2010; 43: 150-158. http://dx.doi.org/10.1016/j.clinbiochem.2009.07.020

[3] COHEN HT, MCGOVERN FJ. Renal-cell carcinoma. N Engl J Med 2005; 353: 2477-2490. http://dx.doi.org/10.1056/ NEJMra043172
[4] DUTCHER JP. Recent developments in the treatment of renal cell carcinoma. Ther Adv Urol 2013; 5: 338-353. http://dx.doi. org/10.1177/1756287213505672

[5] LAM JS, LEPPERT JT, FIGLIN RA, BELLDEGRUN AS. Role of molecular markers in the diagnosis and therapy of renal cell carcinoma. Urology 2005; 66: 1-9. http://dx.doi.org/10.1016/j. urology.2005.06.112

[6] SIONOV RV. MicroRNAs and Glucocorticoid-Induced Apoptosis in Lymphoid Malignancies. ISRN Hematol 2013; 2013: 348212. http://dx.doi.org/10.1155/2013/348212

[7] GARZON R, CROCE CM. MicroRNAs and cancer: introduction. Semin Oncol 2011; 38: 721-723. http://dx.doi. org/10.1053/j.seminoncol.2011.08.008

[8] INUI M, MARTELLO G, PICCOLO S. MicroRNA control of signal transduction. Nat Rev Mol Cell Biol 2010; 11: 252-263. http://dx.doi.org/10.1038/nrm2868

[9] KHELLA HW, WHITE NM, FARAGALLA H, GABRIL M, BOAZAK $M$ et al. Exploring the role of miRNAs in renal cell carcinoma progression and metastasis through bioinformatic and experimental analyses. Tumour Biol 2012; 33: 131-140. http://dx.doi.org/10.1007/s13277-011-0255-5

[10] HUANG Y, DAI Y, YANG J, CHEN T, YIN Y et al. Microarray analysis of microRNA expression in renal clear cell carcinoma. Eur J Surg Oncol 2009; 35: 1119-1123. http://dx.doi. org/10.1016/j.ejso.2009.04.010

[11] JUAN D, ALEXE G, ANTES T, LIU H, MADABHUSHI A et al. Identification of a microRNA panel for clear-cell kidney cancer. Urology 2010; 75: 835-841. http://dx.doi.org/10.1016/j. urology.2009.10.033

[12] WALLIS CJ, GORDANPOUR A, BENDAVID JS, SUGAR L, NAM RK et al. MiR-182 Is Associated with Growth, Migration and Invasion in Prostate Cancer via Suppression of FOXO1. J Cancer 2015; 6: 1295-1305. http://dx.doi.org/10.7150/ jca. 13176

[13] SEGURA MF, HANNIFORD D, MENENDEZ S, REAVIE L, ZOU X et al. Aberrant miR-182 expression promotes melanoma metastasis by repressing FOXO3 and microphthalmia-associated transcription factor. Proc Natl Acad Sci U S A 2009; 106: 1814-1819. http://dx.doi.org/10.1073/pnas.0808263106

[14] WANG YQ, GUO RD, GUO RM, SHENG W, YIN LR. MicroRNA-182 promotes cell growth, invasion, and chemoresistance by targeting programmed cell death 4 (PDCD4) in human ovarian carcinomas. J Cell Biochem 2013; 114: 1464-1473. http://dx.doi.org/10.1002/jcb. 24488

[15] LOPEZ-BELTRAN A, SCARPELLI M, MONTIRONI R, KIRKALI Z. 2004 WHO classification of the renal tumors of the adults. Eur Urol 2006; 49: 798-805. http://dx.doi. org/10.1016/j.eururo.2005.11.035

[16] BARANWAL S, ALAHARI SK. miRNA control of tumor cell invasion and metastasis. Int J Cancer 2010; 126: 1283-1290. http://dx.doi.org/10.1002/ijc.25014

[17] DYKXHOORN DM. MicroRNAs and metastasis: little RNAs go a long way. Cancer Res 2010; 70: 6401-6406. http://dx.doi. org/10.1158/0008-5472.CAN-10-1346

[18] IORIO MV and CROCE CM. MicroRNAs in cancer: small molecules with a huge impact. J Clin Oncol 2009; 27: 58485856. http://dx.doi.org/10.1200/JCO.2009.24.0317 
[19] SUN Y, FANG R, LI C, LI L, LI F et al. Hsa-mir-182 suppresses lung tumorigenesis through down regulation of RGS17 expression in vitro. Biochem Biophys Res Commun 2010; 396: 501-507. http://dx.doi.org/10.1016/j. bbrc.2010.04.127

[20] TANG L, CHEN F, PANG E-J, ZHANG Z-Q, JIN B-W et al. MicroRNA-182 inhibits proliferation through targeting oncogenic ANUBL1 in gastric cancer. Oncology reports 2015; 33: 1707-1716. http://dx.doi.org/10.3892/or.2015.3798

[21] WANG J, LI J, SHEN J, WANG C, YANG L et al. MicroRNA182 downregulates metastasis suppressor 1 and contributes to metastasis of hepatocellular carcinoma. BMC Cancer 2012; 12: 227. http://dx.doi.org/10.1186/1471-2407-12$\underline{227}$

[22] XU X, WU J, LI S, HU Z, XU X et al. Downregulation of microRNA-182-5p contributes to renal cell carcinoma proliferation via activating the AKT/FOXO3a signaling pathway. Mol Cancer 2014; 13: 109. http://dx.doi.org/10.1186/14764598-13-109

[23] HA N-H, FARAJI F, HUNTER KW. Mechanisms of Metastasis. In: editors. Cancer Targeted Drug Delivery. Springer; 2013. 435-458.

[24] HUNTER KW, CRAWFORD NP, ALSARRAJ J. Mechanisms of metastasis. Breast Cancer Res 2008; 10 Suppl 1: S2. http:// dx.doi.org/10.1186/bcr1988

[25] WEIGELT B, PETERSE JL, VAN ,T VEER LJ. Breast cancer metastasis: markers and models. Nat Rev Cancer 2005; 5: 591-602. http://dx.doi.org/10.1038/nrc1670

[26] PSAILA B, LYDEN D. The metastatic niche: adapting the foreign soil. Nat Rev Cancer 2009; 9: 285-293. http://dx.doi. org/10.1038/nrc2621

[27] OUBAN A, MURACA P, YEATMAN T, COPPOLA D. Expression and distribution of insulin-like growth factor-1 receptor in human carcinomas. Hum Pathol 2003; 34: 803-808. http:// dx.doi.org/10.1016/S0046-8177(03)00291-0

[28] PERETZ S, KIM C, ROCKWELL S, BASERGA R, GLAZER PM. IGF1 receptor expression protects against microenvironmental stress found in the solid tumor. Radiat Res 2002; 158: 174-180. http://dx.doi.org/10.1667/0033-7587(2002)158[0174:IREPAM]2.0.CO;2

[29] ANNUNZIATA M, GRANATA R, GHIGO E. The IGF system. Acta Diabetol 2011; 48: 1-9. http://dx.doi.org/10.1007/ s00592-010-0227-z

[30] WERNER H, BRUCHIM I. The insulin-like growth factor-I receptor as an oncogene. Arch Physiol Biochem 2009; 115: 58-71. http://dx.doi.org/10.1080/13813450902783106

[31] SAMANI AA, YAKAR S, LEROITH D, BRODT P. The role of the IGF system in cancer growth and metastasis: overview and recent insights. Endocr Rev 2007; 28: 20-47. http://dx.doi. org/10.1210/er.2006-0001

[32] LI R, POURPAK A, MORRIS SW. Inhibition of the insulin-like growth factor-1 receptor (IGF1R) tyrosine kinase as a novel cancer therapy approach. J Med Chem 2009; 52: 4981-5004. http://dx.doi.org/10.1021/jm9002395

[33] GONG Y, REN J, LIU K, TANG LM. Tumor suppressor role of miR-133a in gastric cancer by repressing IGF1R. World J Gastroenterol 2015; 21: 2949-2958. http://dx.doi.org/10.3748/ wjg.v21.i10.2949

[34] SU J, LIANG H, YAO W, WANG N, ZHANG S et al. MiR-143 and MiR-145 regulate IGF1R to suppress cell proliferation in colorectal cancer. PLoS One 2014; 9: e114420. http://dx.doi. org/10.1371/journal.pone. 0114420

[35] WANG T, GE G, DING Y, ZHOU X, HUANG Z et al. MiR503 regulates cisplatin resistance of human gastric cancer cell lines by targeting IGF1R and BCL2. Chin Med J (Engl) 2014; 127: 2357-2362. 